\title{
Smoking and psychopathology increasingly associated in recent birth cohorts
}

\author{
Ardesheer Talati ${ }^{a, b}, *$, Priya J. Wickramaratne ${ }^{a, b}$, Katherine M. Keyes ${ }^{\mathrm{e}}$, \\ Deborah S. Hasin ${ }^{\mathrm{a}, \mathrm{c}, \mathrm{e}, 1}$, Frances R. Levin ${ }^{\mathrm{a}, \mathrm{d}, 1}$, Myrna M. Weissman ${ }^{\mathrm{a}, \mathrm{b}, \mathrm{e}, 1}$ \\ a Department of Psychiatry, Columbia University, New York, NY 10032, United States \\ ${ }^{\mathrm{b}}$ Divisions of Epidemiology, New York State Psychiatric Institute, New York, NY 10032, United States \\ ${ }^{\mathrm{c}}$ Divisions of Clinical Phenomenology, New York State Psychiatric Institute, New York, NY 10032, United States \\ d Divisions of Substance Abuse, New York State Psychiatric Institute, New York, NY 10032, United States \\ e Division of Epidemiology, Mailman School of Public Health, Columbia University, New York, NY 10032, United States
}

\section{A R T I C L E I N F O}

\section{Article history:}

Received 20 June 2013

Received in revised form 31 July 2013

Accepted 27 August 2013

Available online 5 September 2013

\section{Keywords:}

Smoking

Nicotine dependence

Drug dependence

Cohort

Anxiety

Depression

\begin{abstract}
A B S T R A C T
Background: In recent decades, smoking has become an increasingly non-normative behavior. Because deviant behaviors are associated with greater clinical and genetic risks, current-generation smokers may have greater concentrations of psychiatric comorbidity than previous generations. We examined this question empirically by testing whether associations between measures of smoking, psychiatric diagnoses, and risk-associated personality traits, increased across seven birth-cohorts of the 20th century. Method: 4326 subjects from a cross-sectional NIMH control sample were categorized into one of seven groups based on birth (born before 1930, and 1930s-80s) and one of three smoking levels (lifetime dependent smoker, never dependent smoker, never smoker). Smoking and ND were assessed using the Fagerstrom Test for Nicotine Dependence; psychiatric diagnoses (drug and alcohol dependence, major depression, and generalized anxiety disorder) using the Composite International Diagnostic Interview-Short Form, and personality traits (neuroticism and extraversion) with the Eysenck Personality Questionnaire.

Result: Lifetime prevalence of smoking decreased across the seven cohorts. Associations between smoking and drug dependence, generalized anxiety, and neuroticism, as well as total psychiatric comorbidity, were greater in more recent cohorts [smoking-by-cohort interaction: $p<0.01$ ], with greatest increases contributed by nicotine-dependent smokers. Smoking was also independently associated with alcohol dependence and depression, but these associations did not significantly vary across cohorts. Conclusions: More recent generations included fewer persons who smoked, but their smoking was associated with greater psychiatric morbidity. Failure to account for systematic variation in comorbidity across smoking cohorts may lead to unwanted heterogeneity in clinical, and possibly genetic, studies of nicotine dependence.
\end{abstract}

(C) 2013 Elsevier Ireland Ltd. All rights reserved.

\section{Introduction}

The 20th century witnessed substantial changes in tobacco use in the United States. During its earlier decades, tobacco use increased, driven by several factors including advances in cigarette manufacturing technology, free cigarette distribution during the

\footnotetext{
is Supplementary material can be found by accessing the online version of this paper at http://dx.doi.org and by entering http://dx.doi.org/10.1016/j. drugalcdep.2013.08.025.

* Corresponding author at: Department of Psychiatry, Columbia University \& New York State Psychiatric Institute, 1051 Riverside Drive, Unit 24/Room 2428, New York, NY 10032, United States. Tel.: +1 212543 5796; fax: +1 2125683534.

E-mail addresses: at2071@columbia.edu, aditalati@gmail.com (A. Talati).

1 These authors contributed equally to this work.
}

World Wars, increased advertising, and growing acceptability of women smokers (Bergen and Caporaso, 1999; Giovino, 2007; Lopez et al., 1994; Milmore and Conover, 1956). Trends began to shift in the 1950s following evidence linking tobacco use to lung cancer and heart disease (Doll, 1999; Murphy and Di Cesare, 2012). In the mid1960s, the US government issued the first Surgeon General's warnings, and began a series of anti-smoking efforts including required labeling and restricted advertising. Subsequent laws, both in the US, and several other nations, have progressively restricted smoking in public spaces and increased taxation on tobacco products. Prevalence and incidence of smoking have also gradually declined in recent decades, with Centers for Disease Control and Prevention reports estimating only a fifth of the US population as being current smokers in 2010, as compared to nearly half of the population in the 1950s (Center for Disease Control and Prevention, 2011). 
As the adverse consequences of tobacco use become universally recognized, smoking has been rendered an increasingly stigmatized behavior (Chapman and Freeman, 2008; Chassin et al., 2007; Stuber et al., 2008). Existing evidence suggests that as use of substances becomes less normative and more deviant, individuals who engage in use of those substances have greater levels of antisociality and other traits related to psychiatric disorders (Little et al., 2008; Room, 2005). Thus, more recently born smokers may represent a phenotype with greater propensity to psychiatric traits and disorders than smokers from previous generations when smoking was normative (Chassin et al., 2007; Costa et al., 2010; Stuber et al., 2008). Such changes have obvious public health implications, as they identify sub-groups requiring greatest intervention. But they can also have unappreciated research consequences, particularly if psychiatric comorbidity varies systematically across different subgroups of smokers, but this heterogeneity is not taken into account. And if recent smokers increasingly deviate from their non-smoking counterparts genetically - either by virtue of greater psychiatric comorbidity or by having higher loadings on genetically-underpinned traits such as antisociality or impulsivity (Cuartas Arias et al., 2011; Pavlov et al., 2012), failure to systematically account for these differences could confound genetic analyses, or lead to identification of markers associated with comorbid diagnoses or traits rather than nicotine dependence. A Swedish twin study alluded to such an effect, reporting that heritability estimates for tobacco use among females increased several-fold across the first 50 years of the 20th century (Kendler et al., 2000).

Although numerous studies conducted at various time points have consistently documented relationships between smoking and various psychiatric disorders (Breslau et al., 1991; Lasser et al., 2000; McClave et al., 2010; Upadhyaya et al., 2002), few have explicitly explored changes in associations between smoking and psychopathology over time. One US population-based study found no significant associations between smoking and depression in the 1950 s and 1970s but a three-fold association in the 1990s (Murphy et al., 2003). A more recent Australian study found no changes in the associations between smoking and overall psychological distress over a ten-year period (Gartner et al., 2012; Mathews et al., 2010). These studies however each examined only narrow outcomes (depression, or psychological distress) and varying timeperiods.

We here examined associations between lifetime smoking and a range of psychiatric outcomes (drug, alcohol, depressive, and anxiety disorders, as well as two smoking-related personality traits, neuroticism and extraversion) in the National Institute of Mental Health's Molecular Genetics of Schizophrenia 2 (MGS2) control sample (Sanders et al., 2010). Even though MGS2 was conducted at a single time-point in the mid 2000s, it included a large sample $(>4000)$ with births spanning more than seven decades of the 20th century (1920-1980s), as well as detailed information on lifetime tobacco use and select psychiatric diagnoses, which allowed us to examine changes in relationships between smoking and associated psychopathology over several decades. We hypothesized that after accounting for potential confounders, associations between lifetime smoking and psychopathology would increase in more recently-born smokers, and secondarily, given the more severe clinical course associated with substance dependence (Jamal et al., 2012; Martinez-Ortega et al., 2008; Pedersen and von Soest, 2009), that the above increases would be greater among smokers who were ever nicotine-dependent, as compared to those who were not.

\section{Methods}

\subsection{Sample and assessments}

This report is based on 4326 subjects (55\% female; $73 \%$ non-Hispanic Caucasian/27\% non-Hispanic African-American) from the NIMH's MGS2 control sample, collected 2004-2006, and detailed elsewhere (Sanders et al., 2010). Briefly, subjects were recruited by a marketing company under subcontract using research survey methods (Sanders et al., 2010) to serve as controls in association studies of schizophrenia and other Axis I disorders. Subjects with any history of schizophrenia, schizoaffective, or bipolar disorder, or those reporting hallucinations or delusions, were excluded. Informed written consent was obtained by the North Shore University Health System (Sanders et al., 2010). Subjects were assessed online by a demographic questionnaire and three assessments, as detailed below.

The Composite International Diagnostic Interview-Short Form (CIDI-SF; Kessler et al., 1996) is a structured diagnostic scale assessing eight psychiatric syndromes: generalized anxiety disorder; social anxiety disorder; specific phobias; obsessive compulsive disorder; panic attacks; agoraphobia; major depression; any drug dependence; and alcohol dependence. (We selected, a priori, four of these: drug dependence, alcohol dependence, major depression, and generalized anxiety disorder.) It can be administered over the telephone or (as was the case here) online, and takes under $10 \mathrm{~min}$ for most participants. The instrument has a stem-branch structure, with initial gate questions skipping out subjects least likely to be cases. Subjects not skipped out then go through the remaining questions, each assessed over lifetime with subjects asked to refer to the period of peak problems. The number of endorsed symptoms is then computed via an algorithm to generate a categorical diagnosis (Walters et al., 2002). The scale was developed as a shortened version of the World Health Organization's fuller Composite International Diagnostic Interview (CIDI). The CIDI itself has high inter-rater and test-retest reliability (Wittchen, 1994) and good diagnostic concordance with psychiatrist-scored DSM checklists (Janca et al., 1992). Discriminant validity of the CIDI-SF vis a vis the parent CIDI indicate, respectively, good to excellent sensitivity/specificity/classification accuracy (drug dependence, 77\%/99\%/98\%; alcohol dependence: 94\%/96\%/95\%; major depression: 90\%/94\%/93\%; generalized anxiety: 97\%/99.8/99.6\%). Diagnostic categories are not mutually exclusive, and do not account for hierarchies or rule-outs, leading to possible over-diagnosis of some conditions (Sanders et al., 2010, see limitations).

Subjects also completed the 12-item neuroticism and extraversion short scales of the revised version of the Eysenck Personality Questionnaire (EPQ-R; Eysenck et al., 1985). Each scale comprises twelve yes/no questions, and has been shown to be comparable to fuller NEO-FFI scales (Larstone et al., 2002). Reliability (Cronbach's alpha) for neuroticism is 0.88 for males, and 0.84 for females; for extraversion, 0.84 and 0.80 respectively. Raw scale scores are converted into $t$ scores, with higher scores indicating greater neuroticism and extraversion.

Subjects completed the Fagerström Test for Nicotine Dependence (FTND; Heatherton et al., 1991), based on the "time in your life when you smoked the most." Subjects who reported smoking $<100$ cigarettes in their life were skipped out of further questions, and coded as never-smokers. Those who reported smoking $\geq 100$ cigarettes lifetime completed remaining FTND questions. If their total FTND score during peak cigarette use was above 4 , that is, they had a moderate or higher likelihood of dependence (Fagerstrom et al., 1990), were classified as ever-dependent smokers; otherwise, never-dependent smokers. The three groups are mutually exclusive, and based only on cigarette use (other tobacco use was not assessed). We also replicated the main results in Table 3a using 'number of daily cigarettes smoked' during peak use, indicating that the results are not dependent upon the above cutoffs used to classify nicotine dependence.

\subsection{Classification of cohorts}

Cohorts were determined by the subject's decade of birth (range 1913-1987; mean 1956; median 1957). Because only 23 subjects were born before 1920, these were collapsed with neighboring group, resulting in seven mutually exclusive groups: born before $1930(n=239), 1930$ s $(n=486), 1940$ s $(n=756), 1950 \mathrm{~s}(n=948)$, 1960s $(n=923), 1970$ s $(n=687)$, or 1980s $(n=287)$. We also replicated the overall smoker $\times$ cohort interactions shown in Table 3 excluding subjects over 50 years, to minimize the possibility that older-cohorts were being preferentially populated with healthier subjects due to tobacco related mortality.

\subsection{Statistical analyses}

No subjects were missing diagnostic or smoking variables, and only $4(<0.1 \%)$ missing trait scores. Main outcomes included four lifetime psychiatric diagnoses, treated as binary outcomes and modeled using logistic regression, and two personality traits, treated as continuous outcomes and modeled using linear regression.

The primary hypothesis, that the relationship between smoking and psychopathology increased in more recently born cohorts, was formally tested by fitting a model with a three-level smoker term, a linear cohort term, and a smoker-bycohort interaction term. The significance of the omnibus interaction term was used to test the null hypothesis that any smoking and cohort effects are independent of each other. For outcomes significantly predicted by overall cohort-by-smoke interactions, we investigated relative contributions of the never-dependent and 


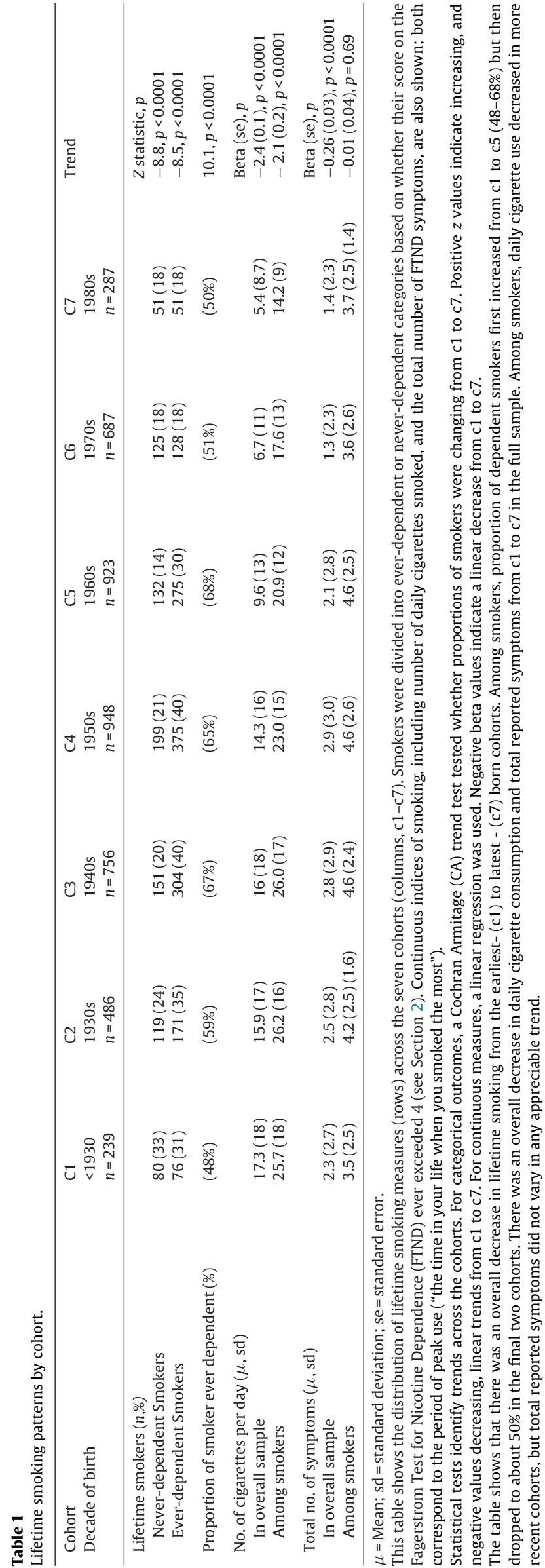

ever-dependent smokers (secondary hypothesis) using pair-wise comparisons (see Supplement 1 for details ${ }^{1}$ ).

All analyses were conducted in SAS (Cary, NC). Gender, race, and education were included in all models, given that temporal changes in smoking behaviors may manifest differently across demographic strata (Docherty and McNeill, 2012; Lund et al., 2011). Education was used to adjust for socioeconomic status, as employment, income, and marital status were assessed only for the current period, and their distributions would themselves systematically vary by cohort (e.g., earliest-born cohorts being disproportionately unemployed or widowed). Distributions of demographic variables by cohort and smoking strata are shown in Supplement $2^{2}$.

\section{Results}

\subsection{Lifetime smoking patterns across cohorts}

We first examined whether lifetime tobacco use itself varied across the seven cohorts. As shown in Table 1, the rates of smoking and nicotine dependence each decreased from earlier- to laterborn (c1-c7) cohorts. The proportion of smokers who were nicotine dependent increased by $20 \%$ (from 48 to 68\%) across the first five cohorts, but then dropped to $51 \%$ and $50 \%$ respectively in the last two cohorts. Subjects in more recent cohorts also reported smoking fewer cigarettes daily during peak use than earlier-born cohorts: maximum number of symptoms however did not vary appreciably across cohorts.

\subsection{Associations between lifetime smoking and psychopathology across cohorts}

We first plotted rates of each outcome by each birth cohort and smoking stratum, in order to visualize changes in rates of psychopathology across cohorts by levels of smoking. As shown in Table 2 and Fig. 1, three trends emerged: (1) later-born cohorts had higher rates of each diagnosis than earlier-born ones (evidenced by the positive slopes of each line in Fig. 1); (2) within any given cohort, smokers had higher diagnostic rates than non-smokers; among smokers, those with nicotine dependence had the highest rates; and (3) the associations between smoking and diagnoses were not constant across cohorts, as reflected by the non-parallel nature of the lines. (Although we focus on diagnoses, given their clinical utility, similar patterns were observed using number of symptoms; see Supplement $3^{3}$ ). The same patterns above were identified for neuroticism, but not extraversion (Table 2, Fig. 1).

We next formally tested whether the associations between smoking and outcome were increasing across the seven cohorts. After adjusting for gender, race, and education, there was a significant overall smoker-by-cohort interaction (Table 3, top) for drug dependence (Wald $\chi_{(2)}{ }^{2}=13.28, p=0.0013$ ), generalized anxiety $\left(\chi_{(2)}{ }^{2}=7.98, p=0.019\right)$, neuroticism $\left(F_{(2)}=11.74, p<0.0001\right)$ and extraversion $\left(F_{(2)}=3.27, p=0.038\right)$. No interactions were observed for alcohol dependence or major depression, and post hoc analyses did not identify any formal gender differences for any outcome.

For outcomes significantly predicted by the interaction between smoking and cohort, we further examined the whether the magnitude of the interaction varied by type of smoker. For drug dependence, changes in the associations between smoking and outcome were similar among never-dependent $(\beta=0.26, p=0.009)$

\footnotetext{
1 Supplementary material can be found by accessing the online version of this paper at http://dx.doi.org and by entering http://dx.doi.org/10.1016/j. drugalcdep.2013.08.025.

2 Supplementary material can be found by accessing the online version of this paper at http://dx.doi.org and by entering http://dx.doi.org/10.1016/j. drugalcdep.2013.08.025.

3 Supplementary material can be found by accessing the online version of this paper at http://dx.doi.org and by entering http://dx.doi.org/10.1016/j. drugalcdep.2013.08.025.
} 
Table 2

Associations between lifetime smoking, psychopathology, and personality traits across seven cohorts.

\begin{tabular}{|c|c|c|c|c|c|c|c|}
\hline Cohort & $\mathrm{c} 1$ & $\mathrm{c} 2$ & c3 & $\mathrm{c} 4$ & c5 & c6 & c7 \\
\hline Decade of birth & $\begin{array}{l}<1930 \\
n=239\end{array}$ & $\begin{array}{l}1930 \mathrm{~s} \\
n=486\end{array}$ & $\begin{array}{l}1940 \mathrm{~s} \\
n=756\end{array}$ & $\begin{array}{l}1950 \mathrm{~s} \\
n=948\end{array}$ & $\begin{array}{l}1960 \mathrm{~s} \\
n=923\end{array}$ & $\begin{array}{l}1970 \mathrm{~s} \\
n=687\end{array}$ & $\begin{array}{l}1980 \text { s } \\
n=287\end{array}$ \\
\hline \multicolumn{8}{|c|}{ Drug dependence $^{\mathrm{a}}$ [lifetime rates, $\left.n(\%)\right]$} \\
\hline Never smokers & $1(1.2)$ & $3(1.5)$ & $5(1.7)$ & $22(5.9)$ & $33(6.4)$ & $18(4.2)$ & $10(5.4)$ \\
\hline Never-dependent smokers & $1(1.3)$ & 0 & $12(7.8)$ & $42(21.1)$ & $26(19.7)$ & $27(21.6)$ & $11(21.6)$ \\
\hline Ever-dependent smokers & $1(1.3)$ & $3(1.8)$ & $34(11.2)$ & $119(31.7)$ & $91(33.1)$ & $32(25)$ & $19(37.3)$ \\
\hline \multicolumn{8}{|c|}{ Alcohol dependence [lifetime rates, $n(\%)]$} \\
\hline Never smokers & $2(2.4)$ & $12(6.1)$ & $24(8.0)$ & $45(12.0)$ & $101(19.6)$ & $48(11.1)$ & $25(13.5)$ \\
\hline Never-dependent smokers & $8(10)$ & $10(8.4)$ & $30(19.9)$ & $46(23.1)$ & $27(20.4)$ & $50(40)$ & $10(19.6)$ \\
\hline Ever-dependent smokers & $16(21.1)$ & $49(28.7)$ & $99(32.6)$ & $145(38.8)$ & $134(48.7)$ & $50(39.1)$ & $21(41.2)$ \\
\hline \multicolumn{8}{|c|}{ Major depression [lifetime rates, $n(\%)$ ] } \\
\hline Never smokers & $4(4.8)$ & $7(3.6)$ & $39(13.0)$ & $62(16.6)$ & $61(11.8)$ & $57(13.1)$ & $28(15.1)$ \\
\hline Never-dependent smokers & $4(5.0)$ & $6(5.0)$ & $15(9.9)$ & $36(18)$ & $22(16.7)$ & $21(16.8)$ & $11(21.6)$ \\
\hline Ever-dependent smokers & $4(5.3)$ & $23(13.5)$ & $54(17.8)$ & $9(25.3)$ & $84(30.6)$ & $41(32.0)$ & $12(23.5)$ \\
\hline \multicolumn{8}{|c|}{ Generalized anxiety disorder [lifetime rates, $n(\%)$ ] } \\
\hline Never smokers & $5(6.0)$ & $14(7.1)$ & $43(14.3)$ & $79(21.1)$ & $79(15.3)$ & $72(16.6)$ & $31(16.8)$ \\
\hline Never-dependent smokers & $3(3.8)$ & $7(5.9)$ & $24(15.9)$ & $45(26.6)$ & $26(19.7)$ & $31(24.8)$ & $14(27.5)$ \\
\hline Ever-dependent smokers & $7(9.2)$ & $24(14.0)$ & $49(6.1)$ & $118(31.5)$ & $96(34.9)$ & $41(32.0)$ & $14(27.5)$ \\
\hline \multicolumn{8}{|l|}{ Neuroticism [mean score (s.d.)] } \\
\hline Never smokers & $42.3(7.2)$ & $42.2(8.6)$ & $44.3(8.9)$ & $45.0(9.7)$ & $43.4(10.0)$ & $43.8(10.9)$ & $44.1(10.4)$ \\
\hline Never-dependent smokers & $42.7(8.2)$ & $42.3(9.6)$ & $45.1(9.7)$ & $46.4(9.8)$ & $44.6(10.9)$ & $46.8(10.6)$ & $45.3(12.5)$ \\
\hline Ever-dependent smokers & $43.9(8.6)$ & $45.2(9.4)$ & $45.4(9.4)$ & $48.8(10.8)$ & $50.0(11.3)$ & $50.6(13.8)$ & $49.5(11.8)$ \\
\hline \multicolumn{8}{|l|}{ Extraversion [mean score (s.d.)] } \\
\hline Never smokers & $53.7(9.5)$ & $55.3(8.9)$ & $52.2(9.3)$ & $51.3(9.2)$ & $51.1(9.4)$ & $47.6(10.0)$ & $47.2(9.7)$ \\
\hline Never-dependent smokers & $55.2(11.8)$ & $55.1(9.6)$ & $53.0(9.0)$ & $53.3(9.5)$ & $52.0(9.3)$ & $50.4(9.5)$ & $47.6(10.2)$ \\
\hline Ever-dependent smokers & $57.1(9.2)$ & $55.2(9.2)$ & $54.5(9.7)$ & $51.8(9.8)$ & $50.6(11.0)$ & $48.0(10.5)$ & $46.9(9.7)$ \\
\hline
\end{tabular}

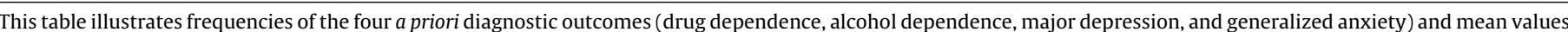

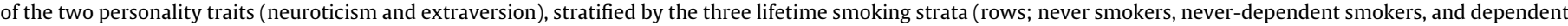
smokers) and seven cohorts which correspond to decade of birth (columns, c1-c7).

a Included dependence to any of the following classes: tranquilizers/nerve pills; amphetamines/stimulants; analgesics/prescription pain killers; inhalants, marijuana; cocaine; LSD/Hallucinogens

and ever-dependent $(\beta=0.33, p=0.0003)$ smokers, with no formal difference between the two smoker groups ( $p=0.46$; Table 3 bottom rows: note, the positive $\beta$ values above reflect that associations between smoking and drug dependence increased in more recent-born cohorts). Similar patterns were obtained for generalized anxiety (never dependent, $\beta=0.16, p=0.02$; ever-dependent, $0.26, p=0.009$, ever- vs. never-dependent, $p=0.91$ ).

For the personality traits, the two smoker groups showed significantly different trajectories (ever- vs. never-dependent smokers, neuroticism, $p=0.009$, extraversion, $p=0.016$ ). For neuroticism, increasing associations with smoking in more recent cohorts were exclusively driven by the dependent smokers, but for extraversion, it was the never-dependent smokers who drove the overall interactions, becoming significantly less introverted across cohorts than either the ever-dependent smokers or the never-smokers (Table 3, bottom).

\section{Discussion}

\subsection{Summary}

Although more recent cohorts included fewer smokers, among those who did smoke, there was a greater burden of psychopathology, particularly drug dependence, generalized anxiety, and neuroticism. Never-dependent smokers appeared an 'intermediary-risk' group for most outcomes, suggesting that studies utilizing only stringent dependence criteria may not fully capture the mental-health problems associated with tobacco use.

\subsection{Potential mechanisms}

Given the cross-sectional study design, subjects born in earlier decades were also older at the time of assessment, and we cannot mechanistically dissociate the contributions of cohort-effects, period-effects, and age-effects from each other (Keyes et al., 2010, see limitations). Age-effects would be predominantly implicated if rates of smoking and psychopathology each increased with age. However, the observation that tobacco use was rarer in more recent cohorts, yet psychiatric comorbidity more common, makes this unlikely. Similarly, period effects (i.e., a change in a specific year in associations between smoking and psychopathology for all individuals regardless of year of birth) are also unlikely, given that both smoking and psychopathology exhibit well-known developmental trajectories (Oesterle et al., 2011; Piontek et al., 2011; Weissman et al., 2006). We posit that cohort effects, though unlikely to account for all of the variance, provide a plausible explanation for the directionality of the findings. The cohort variable here may be latently indexing aspects of social norms, such that changes in norms across the seven cohorts drive some of the observed outcomes. Indeed, broad structural-level factors can modulate individual outcomes (Hughes et al., 1997; Keyes et al., 2011). For example, adolescents in birth cohorts with permissive social norms regarding binge drinking (Keyes et al., 2012) and marijuana use (Keyes et al., 2011) have been shown to be more likely to engage in those behaviors independently of personal attitudes toward these substances, suggesting that social norms provide strong effects on behavior. Negative attitudes to smoking would similarly exert downward societal pressures on smoking (Chapman and Freeman, 2008); more recent smokers may represent increasingly 'hardened' extremes of their cohorts (Chassin et al., 2007; Costa et al., 2010; Stuber et al., 2008), with greater existing mental health problems, or higher loadings on deviant personality traits related to these problems (Stuber et al., 2008). The literature on hardening remains inconclusive, partly stemming from the variation in time periods, populations, outcomes, and operationalization of hardening used across studies (Gartner et al., 2012; Lund et al., 2011; Mathews 


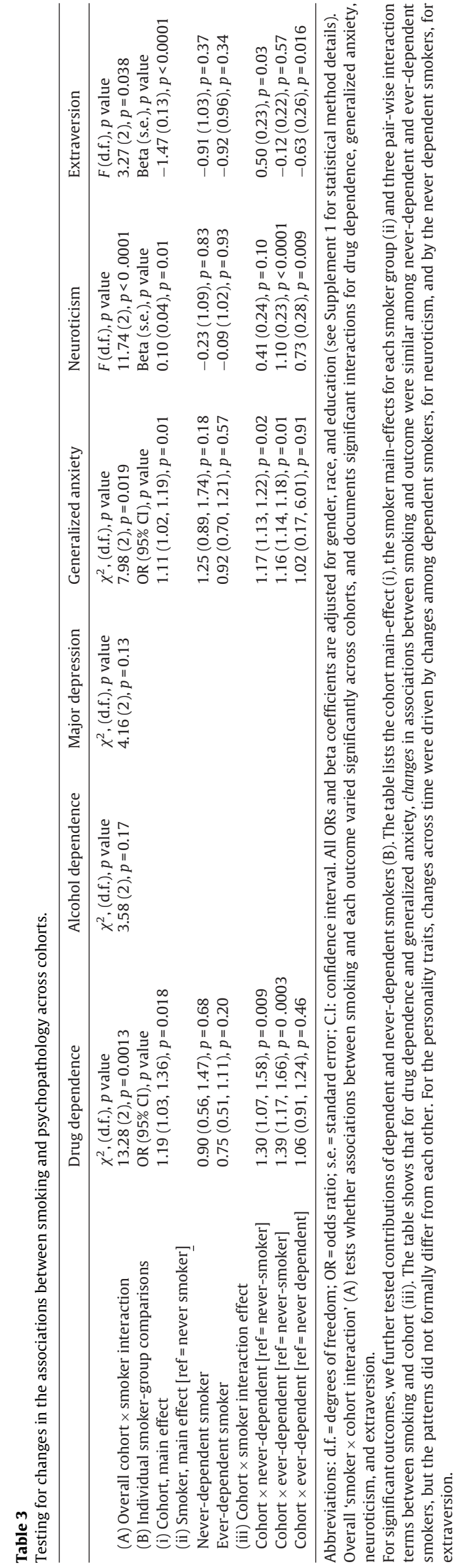

et al., 2010). Our analysis, which examined a wider range of psychiatric and trait outcomes than the aforementioned examples, lends broad support to the hardening hypothesis by showing that smokers from more recent decades carry greater psychiatric comorbidity. But the hypothesis also proffers that more recent smokers should be increasingly dependent which some other studies have noted (Breslau et al., 2001; Goodwin et al., 2009), but ours only partially supports, as proportions of dependence increased across the first five, but then fell in the latest two, cohorts, and have less ability or desire to quit, which we could not test. Future studies containing fine-tuned indices of societal- and individual-level behavioral changes, ideally within a longitudinal design, would allow more comprehensive analysis of these important questions.

\subsection{Smoking, psychopathology, and personality traits}

The strongest findings were observed for drug dependence, with disproportionately increasing frequencies observed among more recent-generation smokers. These patterns are consonant with literature indicating that cigarette smokers over time, especially young cigarette smokers, are becoming increasingly prone to externalizing behaviors (Chassin et al., 2007; Legleye et al., 2010; Little et al., 2008). Similar overall patterns were observed for the internalizing disorders, although it should be noted that for both GAD and $\mathrm{MD}$, rates among the two smoking groups increased across initial cohorts then held constant, and in the final cohort, decreased. This may be because many subjects in the latest-born cohort had not fully passed through the age of greatest risk ( $40 \%$ were $<21$ years). Alternatively, because smoking has now been stigmatized for many years, there may be less incremental change between the more recent cohorts. Second, although only a descriptive observation, Fig. 1 and $S 3^{4}$ show that GAD and MD rates among never-dependent smokers were similar to those of the non-smokers in earlier cohorts, but after 1950, deviate increasingly toward the dependent smokers, suggesting increasing internalizing comorbidity associated with even never-dependent smoking. Overall, the patterns in Fig. 1 are consistent with other studies showing that dependence to nicotine is particularly associated with depressive and anxiety disorders, even after accounting for overall smoking (Breslau et al., 1991; Jamal et al., 2012).

Neuroticism is a known risk factor for both initiation and persistence of smoking (Bates et al., 2011; Munafo and Black, 2007; Terracciano and Costa, 2004). Smoking may alleviate tension in persons with high neuroticism, chronic tobacco use may exacerbate negative affect, or both smoking and neuroticism could be driven by common factors (Cherry and Kiernan, 1976; Munafo and Black, 2007). The literature on extraversion is less clear, with both positive and negative associations with smoking reported, and some studies demonstrating associations with only select dimension (Gilbert, 1995; Terracciano and Costa, 2004). Eyesenk posited that the phenomenology of smoking may vary across traits, with high-neuroticism smokers smoking primarily to control affect, and high-extraversion smokers doing so to heighten stimulation (McManus, 1983). In the present study, more recent cohorts scored higher on neuroticism and the differences were driven predominantly by nicotine-dependent smokers. Despite a statistically significant interaction, we did not find any clearly interpretable patterns for extraversion, although in the more recent cohorts, never-dependent smokers appeared more extraverted than either never-smokers or dependent smokers. Another longitudinal study also noted increasing associations between nicotine dependence

\footnotetext{
4 Supplementary material can be found by accessing the online version of this paper at http://dx.doi.org and by entering http://dx.doi.org/10.1016/j. drugalcdep.2013.08.025.
} 
(a) Diagnoses

Drug Dependence
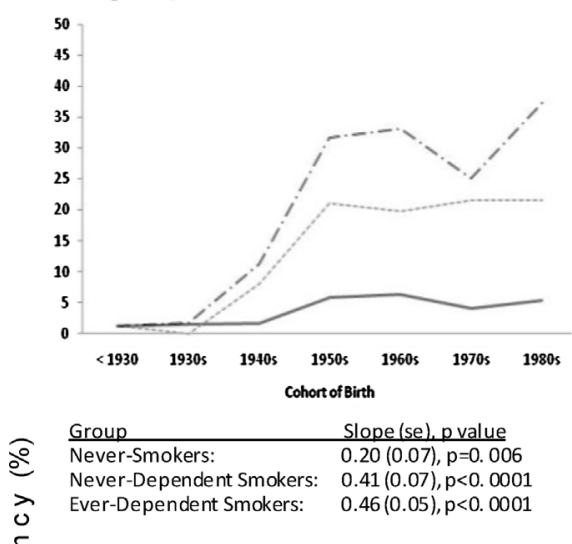

\section{Major Depression}

$\stackrel{50}{1}$

ᄂ 45
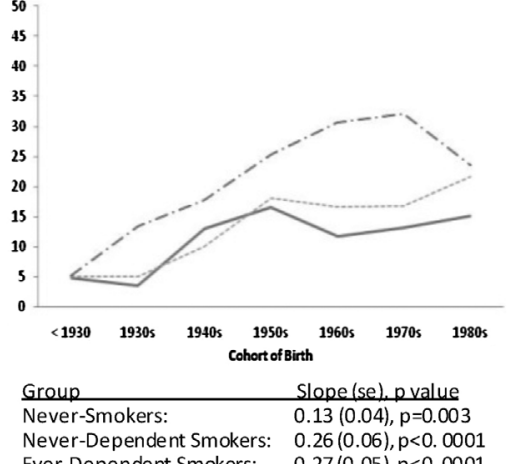

Alcohol Dependence
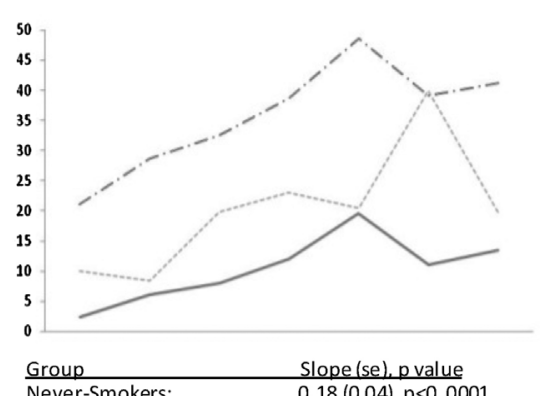
p <0. 0001 $\begin{array}{ll}\text { Ever-Dependent Smokers: } & 0.18(0.04), \mathrm{p}<0.0001\end{array}$

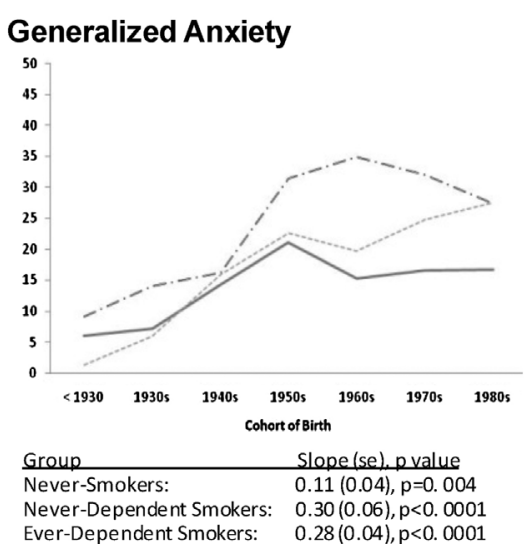

(b) Personality Traits Neuroticism

60
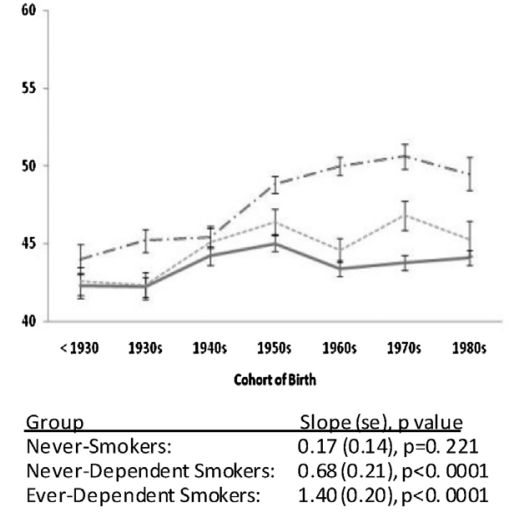

Ever-Dependent Smokers: $\quad 1.40(0.20), \mathrm{p}<0.0001$

\section{Extraversion}

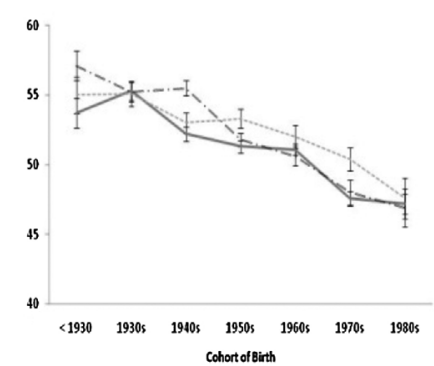

\begin{tabular}{ll} 
Group & Slope (se), p value \\
\hline Never-Smokers: & $-1.43(0.13), p<0.0001$ \\
Never-Dependent Smokers: & $-1.10(0.20), p<0.0001$
\end{tabular}

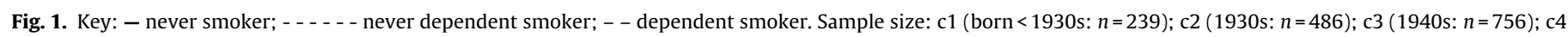

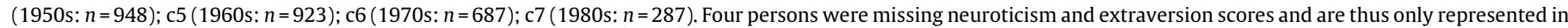

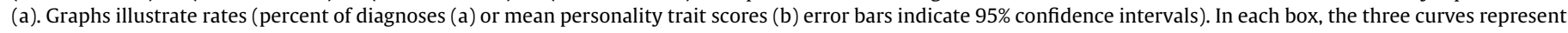

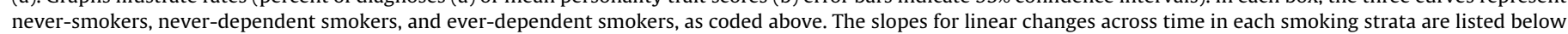
the corresponding graphs. The overall differences in the slopes, formally tested as a statistical interaction between smoking, cohort, and outcome, are shown in Table 3.

and introversion in more recent decades (Murphy et al., 2003). The following points should be considered when interpreting the trait data. First, because only two traits were collected, only a small portion of personality-related variance was likely captured. Second, because the traits (unlike diagnoses) index the assessment period, observed differences may be somewhat vulnerable to ageeffects, as lack of trait stability over time has been noted in some (Billstedt et al., 2013) though not other (Wortman et al., 2012) studies. Finally, because the magnitude of the differences is small, the clinical significance remains unclear.

\subsection{Limitations}

The findings should be interpreted within the context of a number of limitations. First, as discussed earlier, although we focus our interpretation on cohort effects, we cannot formally rule out other time-related effects. For example, increased mortality among older smokers could contribute to the earlier-born groups being populated by disproportionately healthier smokers (Simon et al., 1995). Although we replicated the findings excluding subjects over 50 years (i.e., the most likely contributors to such a differential), we cannot rule out earlier-occurring tobacco-related illness that would likely disproportionately impact heavier smokers (Peto et al., 1992). Another age-effect is retrospective recall bias. Indeed, some retrospective report instability has been documented for smoking (Shillington and Clapp, 2000) as well as other psychopathology (Patten et al., 2012). However, these are unlikely to exclusively account for the observed associations, as prospective studies have reported similar changes in mood and addiction-related disorders over time (Robins et al., 1984; Twenge et al., 2010). Furthermore, the association between smoking and psychopathology would need to be subject to differential recall (Hughes et al., 1997) in order to bias the findings. Finally, social forces operating at specific time-points could also exert differential period effects on smokers and non-smokers regardless of their cohort. Although formal ageperiod-cohort analyses would allow resolution of some of these components, results from such models also are themselves dependent upon a number of assumptions (Keyes et al., 2010; Glenn, 2005). We submit that our data provide an important groundwork for establishing the extent and magnitude of trends of time. Future studies can build on these findings by incorporating information about potential mechanisms that underlie these effects.

The study also does not address temporality. Initial tobacco use could precipitate use of other substances (as postulated by the gateway hypothesis (Kandel et al., 1992), although one may speculate that the role of smoking as a conduit to drug use may itself change as smoking becomes increasingly non-normative) or psychiatric disorders (Choi et al., 1997; Johnson et al., 2000). Alternatively, persons with psychopathology may self-medicate with nicotine (Lerman et al., 1998; Murphy et al., 2003), or both nicotine dependence and other psychopathology could be driven by common genetic or environmental factors (Chen et al., 2012; Jamal et al., 2012). The study also assessed only lifetime smoking. Other temporal factors (onset age, persistence, quitting) were not assessed. 
Finally, the sample only included US non-Hispanic Caucasian and African-American subjects willing to participate in genetic studies, and may not generalize either to the whole US population, or to other parts of the world with differing norms related to smoking (Hughes et al., 1997). Within the sample, higher incomes were over-represented (potentially reflecting the requirement for computer use) and prevalence of all disorders was higher than other epidemiological studies. This could be due to the CIDI-SF instrument's ignoring of diagnostic hierarchy, leading to over-diagnosis [see discussion, p. 862, in Sanders et al., 2010), or the anonymity of the assessment (no direct interface with a clinician) increasing the likelihood of reporting psychopathology, particularly for sensitive topics such as substance use (Fenig et al., 1993; Newman et al., 2002).

\subsection{Implications and future directions}

In the present study, more recent cohorts of smokers were at higher lifetime risk for drug- and anxiety-related psychopathology than either non-smokers from their own cohorts, or smokers from earlier-born cohorts. They clearly constitute a higher-risk group that may benefit from mental health screenings as part of their clinic visits. Although our work does not address cessation, it does suggest that for the large subsamples of younger smokers with psychiatric comorbidity, treatment approaches that combine medication with psychotherapy may be more efficacious. Addressing comorbidity will be increasingly important, as psychiatry becomes more integrated into primary care. Yet, almost a third of physicians still do not ask patients about smoking history (Ferketich et al., 2006; Thorndike et al., 1998); among psychiatrists, rates are even lower (Steinberg et al., 2006; Thorndike et al., 2001) and tobacco guidelines do not emphasize identification of psychiatric comorbidity (Hughes and Weiss, 2009).

Equally important are the study's research implications, especially as this sample is an intended resource for genetic studies (Sanders et al., 2010). Genetic studies of nicotine dependence have not typically explicated birth-cohort differences (Caporaso et al., 2009; Liu et al., 2009; Thorgeirsson et al., 2008). However, if the greater comorbidity in more recent smokers has genetic underpinnings, collapsing subjects across diverse subgroups could increase heterogeneity. Given that individual effect sizes in psychiatric genetics are small (Tobacco and Genetics Consortium, 2010; Heath et al., 2011), this heterogeneity could impact study outcomes. Such issues may compound in meta-analyses, which have variation with and across studies (e.g., Saccone et al., 2010). We suggest that additional information may be obtained if investigators complement their main hypothesis tests with cohort-specific analyses (Kendler et al., 2000).

Finally, data were collected in the mid 2000s. Given increasing assortative mating among smokers (Agrawal et al., 2006), smoking sub-populations are likely to continue deviating from their nonsmoking counterparts. Future studies should continue to follow these deviations epidemiologically, clinically, and genetically.

\section{Author disclosures}

Role of funding source: Access to the sample was provided as part of an NIMH program project P01MH60970 (Weissman, P.I). Drs Talati and Levin are funded by K01DA029598 and K24DA029647 respectively from NIDA; Dr Hasin is funded by K05AA014223 from NIAAA. The NIMH, NIDA and NIAAA had no further role in study design; in the collection, analysis and interpretation of data; in the writing of the report; or in the decision to submit the paper for publication.
Contributors: Dr. Talati designed the study and conducted the analyses and prepared a draft of the manuscript. Drs Talati and Wickramaratne undertook the statistical analyses. All six authors contributed to, and have approved the final manuscript.

Conflicts of interest: Dr. Levin has served as a consultant to GW Pharmaceuticals and receives medication from a clinical trial from US World Meds. Dr. Weissman has received royalties from the Oxford University Press, Perseus Press, the American Psychiatric Association Press, and MultiHealth Systems. None of the above disclosures constitute any conflict with this study. Drs. Talati, Keyes, Hasin, \&Wickramaratne, declare that they have no financial conflicts

\section{Acknowledgements}

Control subjects from the National Institute of Mental Health Schizophrenia Genetics Initiative (NIMH-GI), data and biomaterials are being collected by the "Molecular Genetics of Schizophrenia II" (MGS-2) collaboration. The investigators and coinvestigators are: ENH/Northwestern University, Evanston, IL, MH059571, Pablo V. Gejman, M.D. (Collaboration Coordinator; PI), Alan R. Sanders, M.D.; Emory University School of Medicine, Atlanta, GA, MH59587, Farooq Amin, M.D. (PI); Louisiana State University Health Sciences Center; New Orleans, Louisiana, MH067257, Nancy Buccola, APRN, B.C., M.S.N. (PI); University of California-Irvine, Irvine, CA,MH60870, William Byerley, M.D. (PI); Washington University, St. Louis, MO, U01, MH060879, C. Robert Cloninger, M.D. (PI); University of Iowa, Iowa, IA,MH59566, Raymond Crowe, M.D. (PI), Donald Black, M.D.; University of Colorado, Denver, CO, MH059565, Robert Freedman, M.D. (PI); University of Pennsylvania, Philadelphia, PA, MH061675, Douglas Levinson M.D. (PI); University of Queensland, Queensland, Australia, MH059588, Bryan Mowry, M.D. (PI); Mt. Sinai School of Medicine, New York, NY,MH59586, Jeremy Silverman, Ph.D. (PI). The samples were collected by Vishwajit Nimgaonkar's group at the University of Pittsburgh, as part of a multi-institutional collaborative research project with Jordan Smoller, M.D., D.Sc., and Pamela Sklar, M.D., Ph.D., Massachusetts General Hospital (grant MH 63420). Data and biomaterials used in Study 23 were collected by the University of Pittsburgh and funded by an NIMH grant (Genetic Susceptibility in Schizophrenia, MH 56242) to Vishwajit Nimgaonkar, M.D., Ph.D. Additional Principal Investigators on this grant include Smita Deshpande, M.D., Dr. Ram Manohar Lohia Hospital, New Delhi, India; and Michael Owen, M.D., Ph.D., University of Wales College of Medicine, Cardiff, UK. We thank the families who have participated in and contributed to these studies.

The authors express their gratitude to Annie Rabinovitch, MS, and Paige Endsley, BA, for assistance in the analysis and preparation of this manuscript.

\section{Appendix A. Supplementary data}

Supplementary material related to this article can be found, in the online version, at http://dx.doi.org/10.1016/j.drugalcdep.2013. 08.025 .

\section{References}

Agrawal, A., Heath, A.C., Grant, J.D., Pergadia, M.L., Statham, D.J., Bucholz, K.K., Martin, N.G., Madden, P.A., 2006. Assortative mating for cigarette smoking and for alcohol consumption in female Australian twins and their spouses. Behav. Genet. 36, 553-566.

Bates, C.E., Monahan, J.L., Rhodes, N., 2011. How neuroticism affects responses to anti-smoking messages. Health Commun. 27, 486-497.

Bergen, A.W., Caporaso, N., 1999. Cigarette smoking. J. Natl. Cancer Inst. 91, 1365-1375.

Billstedt, E., Skoog, I., Duberstein, P., Marlow, T., Hallstrom, T., Andre, M., Lissner, L., Bjorkelund, C., Ostling, S., Waern, M., 2013. A 37-year prospective study of 
neuroticism and extraversion in women followed from mid-life to late life. Acta Psychiatr. Scand., http://dx.doi.org/10.1111/acps.12093 (Epub ahead of print).

Breslau, N., Johnson, E.O., Hiripi, E., Kessler, R., 2001. Nicotine dependence in the United States: prevalence, trends, and smoking persistence. Arch. Gen. Psychiatry $58,810-816$

Breslau, N., Kilbey, M., Andreski, P., 1991. Nicotine dependence, major depression, and anxiety in young adults. Arch. Gen. Psychiatry 48, 1069-1074.

Caporaso, N., Gu, F., Chatterjee, N., Sheng-Chih, J., Yu, K., Yeager, M., Chen, C., Jacobs, K., Wheeler, W., Landi, M.T., Ziegler, R.G., Hunter, D.J., Chanock, S., Hankinson, S., Kraft, P., Bergen, A.W., 2009. Genome-wide and candidate gene association study of cigarette smoking behaviors. PLoS ONE 4, e4653.

Center for Disease Control and Prevention, 2011. Vital signs: current cigarette smoking among adults aged $\geq 18$ years United States, 2005-2010. MMWR 60 1207-1212.

Chapman, S., Freeman, B., 2008. Markers of the denormalisation of smoking and the tobacco industry. Tob. Control 17, 25-31.

Chassin, L., Presson, C., Morgan-Lopez, A., Sherman, S.J., 2007. Deviance proneness and adolescent smoking 1980 vs. 2001: has there been a hardening of adolescent smoking? J. Appl. Dev. Psychol. 28, 264-276.

Chen, L.S., Xian, H., Grucza, R.A., Saccone, N.L., Wang, J.C., Johnson, E.O., Breslau, N., Hatsukami, D., Bierut, L.J., 2012. Nicotine dependence and comorbid psychiatric disorders: examination of specific genetic variants in the CHRNA5 A3-B4 nicotinic receptor genes. Drug Alcohol Depend. 123 (Suppl. 1) S42-S51.

Cherry, N., Kiernan, K., 1976. Personality scores and smoking behaviour. A longitudinal study. Br. J. Prev. Soc. Med. 30, 123-131.

Choi, W.S., Patten, C.A., Gillin, J.C., Kaplan, R.M., Pierce, J.P., 1997. Cigarette smoking predicts development of depressive symptoms among U.S. adolescents. Ann. Behav. Med. 19, 42-50.

Costa, M.L., Cohen, J.E., Chaiton, M.O., Ip, D., McDonald, P., Ferrence, R., 2010. Hardcore definitions and their application to a population-based sample of smokers. Nicotine Tob. Res. 12, 860-864.

Cuartas Arias, J.M., Palacio Acosta, C.A., Valencia, J.G., Montoya, G.J., Arango Viana, J.C., Nieto, O.C., Florez, A.F., Camarena Medellin, B.E., Montoya, W.R., Lopez Jaramillo, C.A., Achury, J.G., Fuentes, C.C., Berrio, G.B., Ruiz-Linares, A., 2011. Exploring epistasis in candidate genes for antisocial personality disorder. Psychiatr. Genet. 21, 115-124

Docherty, G., McNeill, A., 2012. The hardening hypothesis: does it matter? Tob. Control 21, 267-268.

Doll, R., 1999. Tobacco: a medical history. J. Urban Health 76, 289-313.

Eysenck, S., Eysenck, H.J., Barrett, P., 1985. A revised version of the Psychoticism Scale. Person. Individ. Diff. 6, 21-29.

Fagerstrom, K.O., Heatherton, T.F., Kozlowski, L.T., 1990. Nicotine addiction and its assessment. Ear Nose Throat J. 69, 763-765

Fenig, S., Levav, I., Kohn, R., Yelin, N., 1993. Telephone vs face-to-face interviewing in a community psychiatric survey. Am. J. Public Health 83, 896-898.

Ferketich, A.K., Khan, Y., Wewers, M.E., 2006. Are physicians asking about tobacco use and assisting with cessation? Results from the 2001-2004 national ambulatory medical care survey, NAMCS. Prev. Med. 43, 472-476.

Gartner, C., Scollo, M., Marquart, L., Mathews, R., Hall, W., 2012. Analysis of national data shows mixed evidence of hardening among Australian smokers. Aust. N. Z. J. Public Health 36, 408-414.

Gilbert, D., 1995. Smoking: Individual Differences, Psychopathology, and Emotion. Taylor \& Francis, Washington, DC

Giovino, G.A., 2007. The tobacco epidemic in the United States. Am. J. Prev. Med. 33, S318-S326.

Glenn, N.D., 2005. Cohort Analysis, Second edition. Sage Publications, Inc., Thousand Oaks, CA

Goodwin, R.D., Keyes, K.M., Hasin, D.S., 2009. Changes in cigarette use and nicotine dependence in the United States: evidence from the 2001-2002 wave of the national epidemiologic survey of alcoholism and related conditions. Am. J. Public Health 99, 1471-1477.

Heath, A.C., Whitfield, J.B., Martin, N.G., Pergadia, M.L., Goate, A.M., Lind, P.A McEvoy, B.P., Schrage, A.J., Grant, J.D., Chou, Y.L., Zhu, R., Henders, A.K., Medland, S.E., Gordon, S.D., Nelson, E.C., Agrawal, A., Nyholt, D.R., Bucholz, K.K. Madden, P.A., Montgomery, G.W., 2011. A quantitative-trait genome-wide association study of alcoholism risk in the community: findings and implications. Biol. Psychiatry 70, 513-518.

Heatherton, T.F., Kozlowski, L.T., Frecker, R.C., Fagerstrom, K.O., 1991. The Fagerstrom test for nicotine dependence: a revision of the Fagerstrom Tolerance Questionnaire. Br. J. Addict. 86, 1119-1127.

Hughes, J.R., Giovino, G.A., Klevens, R.M., Fiore, M.C., 1997. Assessing the generaliz ability of smoking studies. Addiction 92, 469-472.

Hughes, J.R., Weiss, R.D., 2009. Are differences in guidelines for the treatment of nicotine dependence and non-nicotine dependence justified? Addiction 104, $1951-1957$

Jamal, M., Willem Van der Does, A.J., Cuijpers, P., Penninx, B.W., 2012. Association of smoking and nicotine dependence with severity and course of symptoms in patients with depressive or anxiety disorder. Drug Alcohol Depend. 126, 138-146.

Janca, A., Robins, L.N., Bucholz, K.K., Early, T.S., Shayka, JJ. 1992. Comparison of Composite International Diagnostic Interview and clinical DSM-III-R criteria checklist diagnoses. Acta Psychiatr. Scand. 85, 440-443.

Johnson, J.G., Cohen, P., Pine, D.S., Klein, D.F., Kasen, S., Brook, J.S., 2000. Association between cigarette smoking and anxiety disorders during adolescence and early adulthood. JAMA 284, 2348-2351.
Kandel, D.B., Yamaguchi, K., Chen, K., 1992. Stages of progression in drug involvement from adolescence to adulthood: further evidence for the gateway theory. J. Stud. Alcohol 53, 447-457.

Kendler, K.S., Thornton, L.M., Pedersen, N.L., 2000. Tobacco consumption in Swedish twins reared apart and reared together. Arch. Gen. Psychiatry 57, 886-892.

Kessler, R., Andrews, G., Mrozcek, D., Ustun, B., Wittchen, H., 1996. The World Health Organization composite international diagnostic interview short-form, CIDI-SF. Int. J. Methods Psychiatr. Res. 7, 171-185.

Keyes, K.M., Schulenberg, J.E., O’Malley, P.M., Johnston, L.D., Bachman, J.G., Li, G., Hasin, D., 2011. The social norms of birth cohorts and adolescent marijuana use in the United States, 1976-2007. Addiction 106, 1790-1800.

Keyes, K.M., Schulenberg, J.E., O’Malley, P.M., Johnston, L.D., Bachman, J.G., Li, G., Hasin, D., 2012. Birth cohort effects on adolescent alcohol use: the influence of social norms from 1976-2007. Arch. Gen. Psychiatry 69, 1304-1313.

Keyes, K.M., Utz, R.L., Robinson, W., Li, G., 2010. What is a cohort effect? Comparison of three statistical methods for modeling cohort effects in obesity prevalence in the United States, 1971-2006. Soc. Sci. Med. 70, 1100-1108.

Larstone, R., Jang, K.L., Livesley, W.J., Vernon, P.A., Wolf, H., 2002. The relationship between Eysenck's P-E-N model of personlaity, the five-factor model of personality, and traits delineating personality dysfunction. Person. Individ. Diff. 33, 25-37.

Lasser, K., Boyd, J.W., Woolhandler, S., Himmelstein, D.U., McCormick, D., Bor, D.H., 2000. Smoking and mental illness: a population-based prevalence study. JAMA 284, 2606-2610.

Legleye, S., Obradovic, I., Janssen, E., Spilka, S., Le Nezet, O., Beck, F., 2010. Influence of cannabis use trajectories, grade repetition and family background on the schooldropout rate at the age of 17 years in France. Eur. J. Public Health 20, 157-163.

Lerman, C., Caporaso, N., Main, D., Audrain, J., Boyd, N.R., Bowman, E.D., Shields, P.G. 1998. Depression and self-medication with nicotine: the modifying influence of the dopamine D4 receptor gene. Health Psychol. 17, 56-62.

Little, M., Weaver, S.R., King, K.M., Liu, F., Chassin, L., 2008. Historical change in the link between adolescent deviance proneness and marijuana use, 1979-2004. Prev. Sci. 9, 4-16.

Liu, Y.Z., Pei, Y.F., Guo, Y.F., Wang, L., Liu, X.G., Yan, H., Xiong, D.H., Zhang, Y.P., Levy, S., Li, J., Haddock, C.K., Papasian, C.J., Xu, Q., Ma, J.Z., Payne, T.J., Recker, R.R., Li, M.D., Deng, H.W., 2009. Genome-wide association analyses suggested a novel mechanism for smoking behavior regulated by IL15. Mol. Psychiatry 14, 668-680.

Lopez, A.D., Collishaw, N.E., Piha, T., 1994. A descriptive model of the cigarette epidemic in developed countries. Tob. Control 3, 242-247.

Lund, M., Lund, K.E., Kvaavik, E., 2011. Hardcore smokers in Norway 1996-2009. Nicotine Tob. Res. 13, 1132-1139.

Martinez-Ortega, J.M., Jurado, D., Gurpegui, M., 2008. Nicotine dependence vs. daily smoking as a meaningful variable: implications for clinical and epidemiological psychiatric studies. Prog. Neuropsychopharmacol. Biol. Psychiatry 32 1972-1977.

Mathews, R., Hall, W.D., Gartner, C.E., 2010. Is there evidence of 'hardening' among Australian smokers between 1997 and 2007? Analyses of the Australian National Surveys of mental health and well-being. Aust. N. Z. J. Psychiatry 44, 1132-1136.

McClave, A.K., McKnight-Eily, L.R., Davis, S.P., Dube, S.R., 2010. Smoking characteristics of adults with selected lifetime mental illnesses: results from the 2007 National Health Interview Survey. Am. J. Public Health 100, 2464-2472.

McManus, I.C., 1983. 'Smoking, personality and reasons for smoking': a reply to Eysenck. Psychol. Med. 13, 895-896.

Milmore, B.K., Conover, A.G., 1956. Tobacco smoking patterns in the United States: Public Health Monogr. 45. DHEW PHS 463, 107-111.

Munafo, M.R., Black, S., 2007. Personality and smoking status: a longitudinal analysis. Nicotine Tob. Res. 9, 397-404

Murphy, J.M., Horton, N.J., Monson, R.R., Laird, N.M., Sobol, A.M., Leighton, A.H., 2003. Cigarette smoking in relation to depression: historical trends from the Stirling County Study. Am. J. Psychiatry 160, 1663-1669.

Murphy, M., Di Cesare, M., 2012. Use of an age-period-cohort model to reveal the impact of cigarette smoking on trends in Twentieth-century adult cohort mortality in England and Wales. Popul. Stud. Camb. 66, 259-277.

Newman, J.C., Des Jarlais, D.C., Turner, C.F., Gribble, J., Cooley, P., Paone, D., 2002. The differential effects of face-to-face and computer interview modes. Am. J. Public Health 92, 294-297.

Oesterle, S., Hawkins, J.D., Hill, K.G., 2011. Men's and women's pathways to adulthood and associated substance misuse. J. Stud. Alcohol Drugs 72, 763-773.

Patten, S.B., Williams, J.V., Lavorato, D.H., Bulloch, A.G., D’Arcy, C., Streiner, D.L., 2012. Recall of recent and more remote depressive episodes in a prospective cohort study. Soc. Psychiatry Psychiatr. Epidemiol. 47, 691-696.

Pavlov, K.A., Chistiakov, D.A., Chekhonin, V.P., 2012. Genetic determinants of aggression and impulsivity in humans. J. Appl. Genet. 53, 61-82.

Pedersen, W., von Soest, T., 2009. Smoking, nicotine dependence and mental health among young adults: a 13-year population-based longitudinal study. Addiction $104,129-137$

Peto, R., Lopez, A.D., Boreham, J., Thun, M., Heath Jr., C., 1992. Mortality from tobacco in developed countries: indirect estimation from national vital statistics. Lancet 339, 1268-1278

Piontek, D., Kraus, L., Pabst, A., Legleye, S., 2011. An age-period-cohort analysis of cannabis use prevalence and frequency in Germany, 1990-2009. J. Epidemiol. Commun. Health 66, 908-913.

Robins, L.N., Helzer, J.E., Weissman, M.M., Orvaschel, H., Gruenberg, E., Burke Jr., J.D., Regier, D.A., 1984. Lifetime prevalence of specific psychiatric disorders in three sites. Arch. Gen. Psychiatry 41, 949-958. 
Room, R., 2005. Stigma, social inequality and alcohol and drug use. Drug Alcohol Rev. 24, 143-155

Saccone, N.L., Culverhouse, R.C., Schwantes-An, T.H., Cannon, D.S., Chen, X., Cichon, S., Giegling, I., Han, S., Han, Y., Keskitalo-Vuokko, K., Kong, X., Landi, M.T., Ma, J.Z., Short, S.E., Stephens, S.H., Stevens, V.L., Sun, L., Wang, Y., Wenzlaff, A.S., Aggen, S.H., Breslau, N., Broderick, P., Chatterjee, N., Chen, J., Heath, A.C., Heliovaara, M., Hoft, N.R., Hunter, D.J., Jensen, M.K., Martin, N.G., Montgomery, G.W., Niu, T., Payne, T.J., Peltonen, L., Pergadia, M.L., Rice, J.P., Sherva, R., Spitz, M.R., Sun, J., Wang, J.C., Weiss, R.B., Wheeler, W., Witt, S.H., Yang, B.Z., Caporaso, N.E., Ehringer, M.A., Eisen, T., Gapstur, S.M., Gelernter, J., Houlston, R., Kaprio, J., Kendler, K.S., Kraft, P., Leppert, M.F., Li, M.D., Madden, P.A., Nothen, M.M., Pillai, S., Rietschel, M., Rujescu, D., Schwartz, A., Amos, C.I., Bierut, L.J., 2010. Multiple independent loci at chromosome 15q25.1 affect smoking quantity: a meta-analysis and comparison with lung cancer and COPD. PLoS Genet. 6, e1001053.

Sanders, A.R., Levinson, D.F., Duan, J., Dennis, J.M., Li, R., Kendler, K.S., Rice, J.P. Shi, J., Mowry, B.J., Amin, F., Silverman, J.M., Buccola, N.G., Byerley, W.F., Black, D.W., Freedman, R., Cloninger, C.R., Gejman, P.V., 2010. The Internet-based MGS2 control sample: self report of mental illness. Am. J. Psychiatry 167, 854-865.

Shillington, A.M., Clapp, J.D., 2000. Self-report stability of adolescent substance use: are there differences for gender, ethnicity and age? Drug Alcohol Depend. 60, 19-27.

Simon, G.E., VonKorff, M., Ustun, T.B., Gater, R., Gureje, O., Sartorius, N., 1995. Is the lifetime risk of depression actually increasing? J. Clin. Epidemiol. 48, 1109-1118.

Steinberg, M.B., Alvarez, M.S., Delnevo, C.D., Kaufman, I., Cantor, J.C., 2006. Disparity of physicians' utilization of tobacco treatment services. Am. J. Health Behav. 30, 375-386.

Stuber, J., Galea, S., Link, B.G., 2008. Smoking and the emergence of a stigmatized social status. Soc. Sci. Med. 67, 420-430.

Terracciano, A., Costa Jr., P.T., 2004. Smoking and the Five-Factor Model of personality. Addiction 99, 472-481.

Thorgeirsson, T.E., Geller, F., Sulem, P., Rafnar, T., Wiste, A., Magnusson, K.P. Manolescu, A., Thorleifsson, G., Stefansson, H., Ingason, A., Stacey, S.N., Bergthorsson, J.T., Thorlacius, S., Gudmundsson, J., Johsson, T., Jakobsdottir, M.,
Saemundsdottir, J., Olafsdottir, O., Gudmundsson, L.J., Bjornsdottir, G., Kristjansson, K., Skuladottir, H., Isaksson, H.J., Gudbjartsson, T., Jones, G.T., Mueller, T., Gottsater, A., Flex, A., Abden, K.K., de Vegt, F., Mulders, P.F., Isla, D. Vidal, M.J., Asin, L., Saez, B., Murillo, L., Blondal, T., Kolbeinsson, H., Stefansson, J.G., Hansdottir, I., Runarsdottir, V., Pola, R., Lindblad, B., van Rij, A.M. Dieplinger, B., Haltmayer, M., Mayordomo, J.I., Kiemeney, L.A., Matthiasson, S.E., Oskarsson, H., Tyrfingsson, T., Gudbjartsson, D.F., Gulcher, J.R., Jonsson, S. Thorsteinsdottir, U., Kong, A., Stefansson, K., 2008. A variant associated with nicotine dependence, lung cancer and peripheral arterial disease. Nature 452 638-642.

Thorndike, A.N., Rigotti, N.A., Stafford, R.S., Singer, D.E., 1998. National patterns in the treatment of smokers by physicians. JAMA 279, 604-608.

Thorndike, A.N., Stafford, R.S., Rigotti, N.A., 2001. US physicians' treatment of smoking in outpatients with psychiatric diagnoses. Nicotine Tob. Res. 3, 85-91.

Tobacco and Genetics Consortium, 2010. Genome-wide meta-analyses identify multiple loci associated with smoking behavior. Nat. Genet. 42, 441-447.

Twenge, J.M., Gentile, B., DeWall, C.N., Ma, D., Lacefield, K., Schurtz, D.R., 2010. Birth cohort increases in psychopathology among young Americans, 1938-2007: cross-temporal meta-analysis of the MMPI. Clin. Psychol. Rev. 30, 145-154.

Upadhyaya, H.P., Deas, D., Brady, K.T., Kruesi, M., 2002. Cigarette smoking and psychiatric comorbidity in children and adolescents. J. Am. Acad. Child Adolesc. Psychiatry 41, 1294-1305.

Walters, E., Kessler, R.C., Nelson, C.B., Mroczek, D.C., 2002. Scoring the World Health Organization's Composite International Diagnostic Interview Short Form, CIDISF, Revised December 2002. WHO, Geneva.

Weissman, M.M., Wickramaratne, P., Nomura, Y., Warner, V., Pilowsky, D., Verdeli H., 2006. Offspring of depressed parents: 20 years later. Am. J. Psychiatry 163 1001-1008.

Wittchen, H.U., 1994. Reliability and validity studies of the WHO - composite international diagnostic interview, CIDI, a critical review. J. Psychiatr. Res. 28, 57-84.

Wortman, J., Lucas, R.E., Donnellan, M.B., 2012. Stability and change in the Big Five personality domains: evidence from a longitudinal study of Australians. Psychol. Aging 27, 867-874. 